\title{
Noise Reduction-Oriented Flight Aircraft Type
}

\author{
Xia Feng ${ }^{1,2}$, Fangli Sun ${ }^{2}$ and Min $\mathrm{Lu}^{1,2}$ \\ ${ }^{1}$ Information Technology Research Base of CAUC, Tianjin, 300300, China \\ ${ }^{2}$ College of Computer Science and Technology, Civil Aviation of University, \\ Tianjn, 300300, China \\ xfeng@cauc.edu.cn, sunflsuny@163.com,mlu@cauc.edu.cn
}

\begin{abstract}
With the rapid development of civil aviation and raising public awareness of environmental issues, it is extremely crucial to reduce airport noise impact in the vicinity of airports. Reduction of noise at source and operation restrictions are two prominent noise abatement approaches, both of which reduce aircraft noise impact by selecting appropriate aircraft types for flights. However, reduction of noise at source requires high cost while operation restrictions would restrict the ability of full operation of the airport. To tackle with the above issue, the paper studies the problem of aircraft type selection for noise reduction, the target of which is to select aircraft type with the lowest noise from a variety of candidate types. To this end, the paper employs weighted equivalent continuous perceived noise level to measure the noise level, and then utilizes Integrated Noise Model (INM) to calculate noise impact area at the interval of noise level. Experimental results on Beijing International Airport noise monitoring dataset show that the proposed algorithm can indeed obtain the aircraft type with minimal aircraft noise impact.
\end{abstract}

Keywords: aircraft noise abatement ; aircraft type selection; weighted equivalent continuous perceived noise level; Integrated Noise Model (INM)

\section{Introduction}

Airport noise mainly refers to the noise radiation from aircraft during taking off, landing, taxiing, sliding and running engine, which has the characteristics of sudden, intermittent, high sound pressure level, a wide affecting range and long-time influence etc [1]. Airport noise not only interferes with the public daily work, study and rest, but also can damage hearing, induce nervous system and cardiovascular diseases and so on, making the airport noise problems increasingly prominent. Therefore, how to effectively control the impact of airport noise on the areas around the airport is an important subject.

Reduction of noise at source and operation restrictions are two noTable noise abatement approaches, both of which reduce aircraft noise impact by selecting appropriate aircraft types for flights. However, Reduction of noise at source requires high cost while operation restrictions would restrict the ability of full operation of the airport. To tackle with the above issue, the paper studies the problem of aircraft type selection for noise reduction, the target of which is to select aircraft type with the lowest noise from a variety of candidate types. On one hand, the results of this study can help airlines choose appropriate models for a specific flight in order to reduce the environmental impact around the airport areas. On the other hand, it can help administractive departments select the optimal flight time for combination of different flight models, to reduce the impact of aircraft noise.

The main contribution of this paper is as follows: 1) By analyzing the noise data caused during the flight, we point out the phenomenon that different aircraft types perform the same flight in different date is common existing, and based on the T- 
test, we find the noise levels are significantly different when different aircraft types perform the same flight ; 2) Aiming at the appearance that each flight has several candidate types to choose, we conduct a study to choose the minimum noise aircraft types from all the candidate types.

\section{Related Work}

According to the management and research methods of airport noise, The International Civil Aviation Organization (ICAO) analyzes the various measures available to reduce noise using four principal elements [2]: reduction at the source, land-use planning and management, noise-abatement operational procedures, and operation restrictions. Reduction at the source can be further divided into two categories: one is structural modification of aircraft (such as wings, engine) from the perspective of manufacturing industry; the second is the ICAO and countries all of the world have developed relevant noise standards for civil aviation aircraft [3], eliminating greater noise of vintage aircraft. At present, the most stringent noise standard is the fourth generation, whose cumulative noise value of taking off, lateral and approach are smaller of 10EPNdb than third-generation noise standards. Noiseabatement operational procedures is mainly through the optimization about flight path, speed and operation process of aircraft take-off and landing. One hand it can avoid vehicle collision with an obstacle, in order to the plane land and take off safely. On the other hand, it can reduce the environmental influence of the area around the airport during aircraft taking off and landing [4-5]. At present, Noise Abatement Departure Procedures (NADP), established by ICAO in 2006 is often used internationally as noise abatement procedures for departure [6]. And Continuous Descent Approaches (CDA) is often used as noise reduction procedure for approach and landing [7]. In 2006 Prats and his partners generated RNAV trajectory to reduce noise annoyance on residents based on a comprehensive optimization tools [8]. In $2010 \mathrm{~S}$. Alam and his partners studied on a dynamic continuous descent approach methodology (Dynamic CDA) for low airport noise and emission [9]. Operation restrictions is implemented by the specific provisions of the aircraft speed, altitude and thrust in flight procedures, to avoid aircraft flying over densely populated areas. Research of land-use planning and management focuses on airport site selection and design, the design and planning of runway, and design of external noise buffer for residential areas.

Reduction at the source and operation restrictions are two prominent noise abatement methods, both of which reduce aircraft noise impact by selecting appropriate aircraft types for flights. However, reduction at the source requires high cost while operation restrictions would restrict the ability of full operation of the airport. In fact, for a particular airport, when runway trends, the number of flights, weather condition and flight procedures are determined, we can low airport noise by selecting aircraft type for specific flight. But little research has been associated both at home and abroad.

\section{Aircraft Type Selection of Single Flight for Noise Reduction}

\subsection{Research Motivation}

\subsubsection{The Phenomenon of Different Aircraft Types Perform the Same Flight is Widespread}

Through statistical analysis of the observational data of 33 monitoring points at capital airport between August 14, 2007 to August 18, 2010, we find the phenomenon of different aircraft types performing the same flight is widespread. And the ratio of at least two aircraft types performing a same flight is $65.16 \%$, as shown in Figure 1. In Figure 1, 
the horizontal axis represents the number of aircraft types used in the same flight and the vertical axis represents the number of flights performed by different number of aircraft types. The total number of flights is 8924 while the number of at least two aircraft types performing the same flight is 5815 . The statistical results show that the different aircraft types performing the same flight is a common phenomenon, and further explain the study has wide application scenarios.

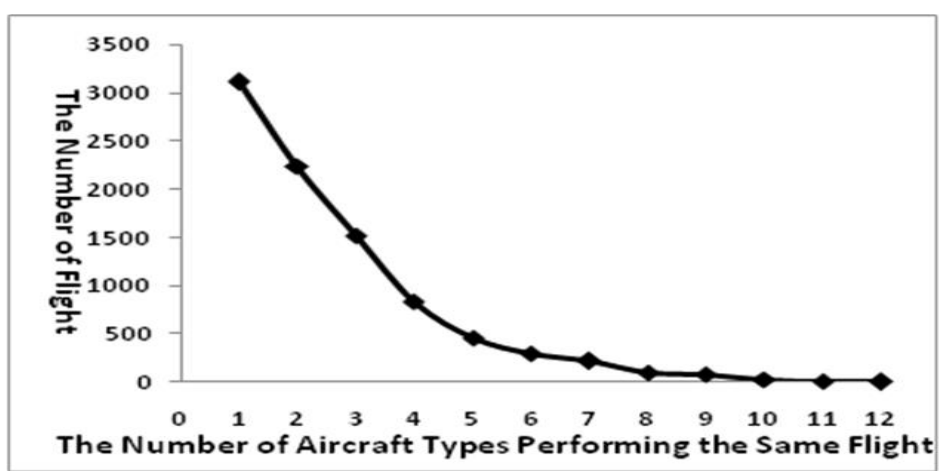

Figure 1. The Number of Different Aircraft Types in the Same Flight

\subsubsection{The Noise Level Generated by Different Aircraft Types for the Same Flight Has Significant Difference}

In order to test whether the noise level generated by different aircraft types performing the same flight has a significant difference, this paper first defines a evaluation index which evaluates noise levels generated by two aircraft types performing the same flight whether have significant differences.

$$
\operatorname{isDiff}\left(t_{i}, t_{j} ; F \text { light }\right)=\left\{\begin{array}{cc}
1 & \exists k, \mathrm{t}_{i}(k) \text { significantly diff from } \mathrm{t}_{j}(k) \\
0 & \text { otherwise }
\end{array}\right.
$$

In equation (1), Flight refers to a specific flight, that is described by the data including departure airport, destination airport, runway, flight track and so on. $t_{i}(k)$ is described as the average noise value generated by aircraft type $t_{i}$ on noise monitor point $k$ for the given

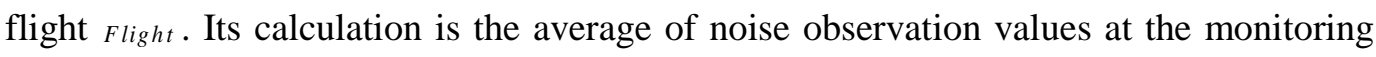
point $k$ for all the same flights $F_{\text {Flight }}$ during August 14, 2007 to August 18, 2010. The intuitive meaning of the above formula is: the necessary and sufficient condition of generating significantly different noise level for two different aircraft types performing the same flight is that there is at least one point in the 33 points, making significantly different noise level on average at this point generated by two different models performing the same flight.

Therefore, this paper tests the significance about difference of average noise level at the same monitoring point for two models performing the same flight using T-test statistical methods. Statistical results are shown in Table 1.

Table 1. The T-Test Results of Noise Differences Between different Aircraft Types in the Same Flight

\begin{tabular}{llccc}
\hline $\begin{array}{c}\text { Number of Theoretical } \\
\text { comparison }\end{array}$ & $\begin{array}{l}\text { Number of T-test } \\
\text { comparison }\end{array}$ & $\begin{array}{c}\text { Confidence } \\
\text { Interval }\end{array}$ & Number of difference & $\begin{array}{c}\text { Occupied } \\
\text { Ratio }\end{array}$ \\
\hline 33528 & 14824 & $90 \%$ & 5412 & $36.51 \%$ \\
33528 & 14824 & $95 \%$ & 4132 & $27.87 \%$ \\
\hline
\end{tabular}


In Table 1, the number of theoretical comparison refers to the total comparative numbers that need to do in one T-test for any two aircraft types performing the same flight in theory, while the number of T-test comparison refers to T-test comparison that is able to carry out actually. We can see from Table 1, the number of theoretical comparison is 33528 and the number of T-test comparison is 14824. The noise monitoring data establishes scheduled time (usually 10s), resulting in noise monitoring point below the noise monitoring data of 10 s are ignored, which makes it focus on noise monitoring data without noise monitoring data existing in some flight event. Some two models cannot carry out test flight T-test, because data of each group for the T-test has at least two noise samples. The actual log of T-test is lower than that in theory, and the root reason is that the noise monitoring data of flight has its scheduled times (usually 10s). So the data at monitoring points which are below 10 s will all be neglected, and this can be lead to some flight events contain nothing at noise monitoring data set. Also, T-test requires more than two noise samples for each data set, not allowing the performance of T-test inspection with two models for some flights. The number of aircraft types which has significant difference on noise is 5412 when the confidence interval is $90 \%$. The proportion is $36.64 \%$ based on the total models. When the confidence interval is $95 \%$, the number and proportion of the aircraft type will be 4132 and $27.87 \%$.

According to the title 2.1.1 and 2.1.2, we can see that it is a common phenomenon with one same flight using different models, also the effect is different. This can be illustrated that the aircraft type selection does have the influence on reducing airport noise, and can be further explained the ubiquity and rationality of the questions mentioned in this paper.

\subsection{Research Motivation}

In the period from August 14th 2007 to August 18th 2010, there are 65.16\% of flights performed by at least two models (see Figure 1) based on 33 monitoring points' observation data near the capital airport. So the main research question of this paper is: for flight with a variety of candidate models, how to choose their models which have minimal impact on aircraft noise. More specifically, when fixing flight, flight path and flight time, how to choose models from a number of candidate models with the smallest aircraft noise models.

Before introducing the optimization objective of this article, this paper first discusses necessary mathematical symbols. The symbol of Fight refers to a specific flight, described by the data of departure airport, destination, runway and track. While $\left\{t_{1}, t_{2}, \ldots, t_{k}\right\}$ refers to all possible candidate aircraft types of flight, in which $\mathrm{k}$ represents the total number of all candidate models for flight Flight . In addition to the above information, we also need to determine an evaluation index to measure the impact of noise. Currently, the number of people affected by noise around airport are often used as evaluation index of noise [10-12], calculated mainly by the distribution of noise, an area affected by noise and the population density of noise area. Because data's of population density are difficult to obtain, the paper took the area effected by aircraft noise as the noise assessment value, in which the index of calculating noise impact is weighted equivalent continuous perceived noise level (WECPNL). The reason of choosing WECPNL is that it adds up noise energy generated by a series of discrete noise aircraft event and it is able to represent noise level around the airport area of certain days such as residential buildings, hospitals, schools and sport venues. It is often used as an important indicator of airport land planning [13-15].The noise value generated by aircraft is divided into three decibel segments, which is less than 70 decibels, between 70 to 75 decibels and greater than 
$75 \mathrm{~dB}$. And the paper further count areas falling into various noise decibel segments. Therefore, the optimization goal of this paper is defined as:

$$
\begin{aligned}
& \min _{t \in\left\{t_{1}, \cdots t_{k}\right\}}\left\{\operatorname{area}\left(L_{\text {wecpnl }}(t)<70 \mathrm{~dB}\right),\right. \\
& \left.\operatorname{area}\left(70 \mathrm{~dB} \leq L_{\text {wecpnl }}(t) \leq 75 \mathrm{~dB}\right), \text { area }\left(L_{\text {wecpnl }}(t)>75 \mathrm{~dB}\right)\right\}
\end{aligned}
$$

In order to calculate the area affected by noise falling into each segment decibels of the noise in formula (2), the article imported the data of radar track, aircraft models and runway to the noise calculation model INM [16], and then calculated the area affected by noise falling into each segment decibels of the noise for different models performing the same flight. The radar tracks of this paper came from radar data from March 22, 2013 to July 14, 2013 at Capital airport. The radar tracks of the same aircraft model performing the same flight in the radar data set came from different dates, leading to different tracks for the same aircraft model performing the same flight. To avoid causing the error of only calculating the noise effect of single radar track on the same model on random, we calculates the area effected by noise for each track on the same aircraft model and flight. And then averages areas affected by noise for each track on the same flight and aircraft model. Finally, the mean of the noise area is used as the area effected by noise of used model for the same flight. The algorithm in this paper is shown in algorithm 1.

\begin{tabular}{|c|c|}
\hline Input & 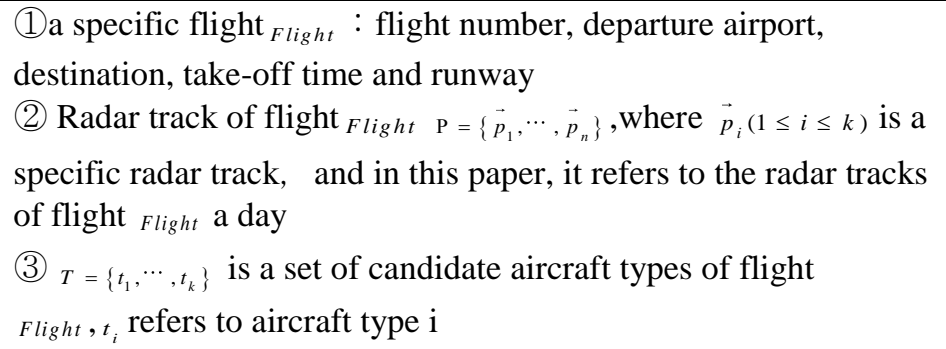 \\
\hline $\begin{array}{l}\text { optimization } \\
\text { procedure }\end{array}$ & $\begin{array}{l}\text { For every aircraft type } t_{i}(1 \leq i \leq k) \\
\text { For every radar track } p_{p_{j}}(1 \leq j \leq m) \\
\text { calculate the noise effecting area of } t_{i} \text { performing the radar } \\
\quad \text { track } p_{p_{j} \quad a_{i j}=\left\{L_{w e c p m l}<70 d B, 70 d B \leq L_{w e c p p l} \leq 75 d B, L_{w e c p m l}>75 d B\right\}} \\
\text { End For } \\
\text { Calculate noise level on average of each aircraft type } t_{i}: \\
\overline{a_{i}}=\frac{1}{m} \sum_{j=1}^{m} a_{i j} \\
\text { End For } \\
\text { Find a model with minimum noise level } \\
t^{*}=\arg \mathrm{min}\left(\bar{a}_{i}\right) \\
\quad t \in\left\{t_{1}, \cdots, t_{k}\right\}\end{array}$ \\
\hline Output & $\begin{array}{l}\text { Output a optimal aircraft type } t_{i}(1 \leq i \leq k) \text {, making the impact of } \\
\text { airport noise minimal }\end{array}$ \\
\hline
\end{tabular}

\section{Algorithm 1}




\section{Experimental Design}

\subsection{Research Motivation}

\subsubsection{Experiment Setting}

The experimental original data of this paper is monitoring data of flight event from August 14, 2007 to August 18, 2010 at Beijing Airport, which records the noise level generated of flight event at 33 monitoring points near the airport each day. Each row of a data set is noise monitoring value at one noise monitoring point on a flight event, including monitoring points, monitoring date and time, noise value, flight number, departure or destination, aircraft type, runway, and the threedimensional distance, two-dimensional distance and height between noise monitoring point and aircraft when the maximum noise occurs. The format is shown in Figure 2.

Monitoring Data of One Fight Event

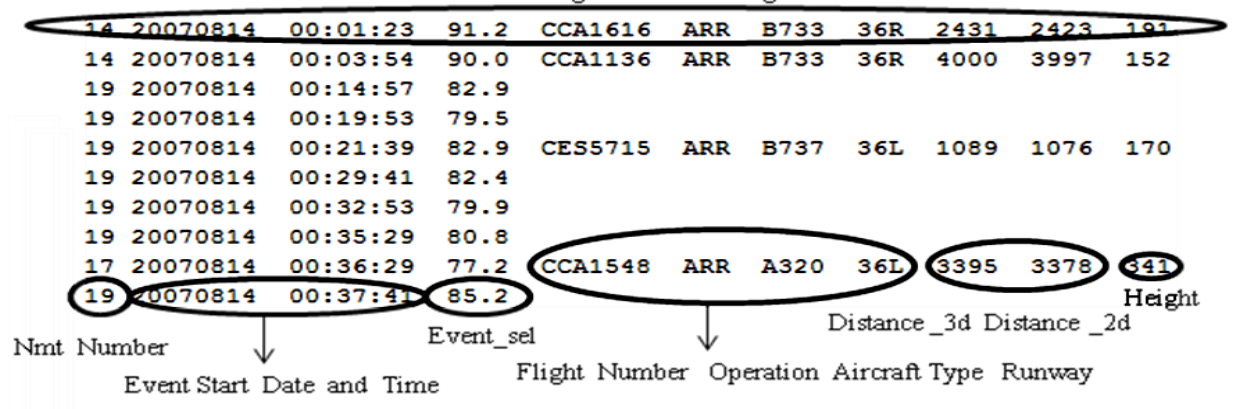

Figure 2. Monitoring Data of Flight Event

In order to calculate the noise effect of one flight event generated by different aircraft types performing the same flight, the paper uses radar track data at the same time. Radar data of this paper refers to flight information that radars get every second from March 22, 2013 to July 17, 2013, which records all of flight information and geographic information of the aircraft within one day. It mainly includes date, time, aircraft number, the code of answering machine, latitude, longitude, height, speed, flight number, aircraft type, departure airport, destination, registration number of aircraft and operation type of aircraft (landing or departure). The data format is shown in Figure 3.

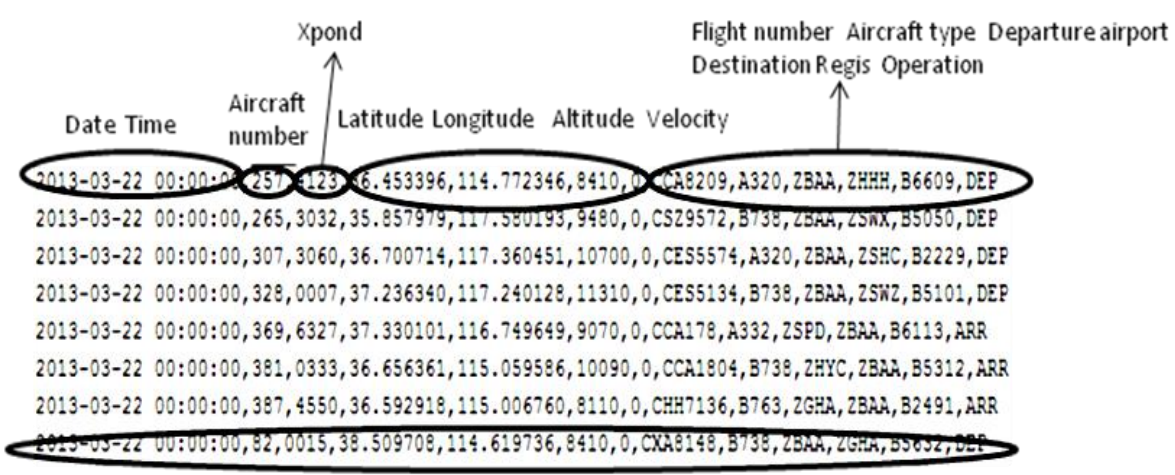

One of original radar data

Figure 3. Original Radar Data and Their Flight Information 


\subsubsection{Data Pretreatment}

In order to carry out the work successfully, we need to pre-process the monitoring data of flight and the radar data in air traffic.

The process is divided into three steps, first to remove the data which have no records about the flight information from the monitoring data set, next to filter the two datasets to ensure they have the same flight, for there exist different flights in both monitoring data set and radar data, and finally to estimate the speed on each radar surveillance, this is because the radar track we put in INM need to provide the speed of the aircraft, but the truth is that in the actual radar data they have no such related information. In this paper, we use the average speed with continuous time in same flight as the instantaneous velocity for the later monitoring point. One core issue is how to calculate the distance between continuous monitoring points. In order to solve this problem, this paper presents a distance formula between two points by latitude and longitude of two points.

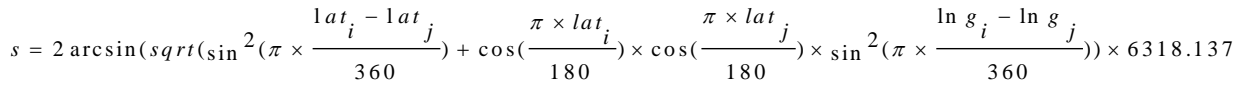

In equation (3), $\ln g_{i}$ and $1 a t_{i}$ are longitude and latitude of monitor point $\mathrm{i}$, while $\ln g_{j}$ and $1 a t_{j}$ are longitude and latitude of monitor point $\mathrm{j}$.

\subsection{Experimental Result}

The number of radar tracks each flight is at least 100, and in order to evaluate noise influence of each flight track, the INM software needs to delineate the real track based on radar track manually, which costs manpower extremely. The paper uses the top nine flights that its occurrence number in the monitor data of flight event is largest as experimental objects, the flight information as shown in Table 2. The noise effected area generated by different aircraft types performing the same flight are shown in Table 3 , in which the bold terms represent the models that generate smallest noise effect. The experimental results show that different models performing the same flight generate different noise affected area. For example, Flight CCA931 uses aircraft of B733, B737, B738, B744, B752, A320, A319, A321 and A330, in which noise area that affected by A319 is smaller than other aircraft types. While A321 and B752 generate relative less noise area than other aircraft types.

Table 2. The Related Information of Nine Flights

\begin{tabular}{llllll}
\hline $\begin{array}{l}\text { Flight } \\
\text { Number }\end{array}$ & Operator & $\begin{array}{l}\text { Departure } \\
\text { Airport }\end{array}$ & Destination & Runway & $\begin{array}{l}\text { Occurrence } \\
\text { Number }\end{array}$ \\
\hline CCA1654 & Approach & ZYTX & ZBAA & 01 & 875 \\
CDG4855 & Approach & ZSYT & ZBAA & 01 & 544 \\
CCA1662 & Approach & ZYCC & ZBAA & 01 & 539 \\
CDG4651 & Approach & ZSQD & ZBAA & 01 & 530 \\
CCA1572 & Approach & ZYHB & ZBAA & 01 & 529 \\
CCA1640 & Approach & ZYYJ & ZBAA & 01 & 527 \\
CCA931 & Approach & ZYTX & ZBAA & 01 & 523 \\
CCA1858 & Approach & ZSSS & ZBAA & 01 & 514 \\
CCA1610 & Approach & ZYCC & ZBAA & 01 & 511 \\
\hline
\end{tabular}


Table 3. The Noise Impactive Area for Different Aircraft Types in the Same Flight

\begin{tabular}{|c|c|c|c|c|c|}
\hline \multirow{2}{*}{$\begin{array}{c}\text { Flight } \\
\text { Number }\end{array}$} & \multirow{2}{*}{$\begin{array}{l}\text { Aircraft } \\
\text { Number }\end{array}$} & \multirow[t]{2}{*}{ Time } & \multicolumn{3}{|c|}{ Area of Noise Impacting } \\
\hline & & & $<70 \mathrm{~dB}$ & {$[70 \mathrm{~dB}, 75 \mathrm{~dB}]$} & $>75 \mathrm{~dB}$ \\
\hline \multirow{4}{*}{ CCA1662 } & A321 & \multirow{4}{*}{$9.129 \mathrm{~h}$} & 28.386 & 0.216 & $\mathbf{0 . 0 5 3}$ \\
\hline & B733 & & 44.775 & 0.187 & 0.04 \\
\hline & B737 & & 52.158 & 0.115 & 0.01 \\
\hline & B738 & & 52.659 & 0.107 & 0.013 \\
\hline \multirow{3}{*}{ CDG4651 } & B733 & \multirow{3}{*}{$7.915 \mathrm{~h}$} & 55.729 & 0.262 & 0.053 \\
\hline & B737 & & 65.308 & 0.168 & 0.016 \\
\hline & B738 & & 67.977 & 0.146 & 0.02 \\
\hline \multirow{3}{*}{ CCA1572 } & B737 & \multirow{3}{*}{$11.16 \mathrm{~h}$} & 39.53 & 0.12 & 0.53 \\
\hline & B738 & & 38.589 & 0.183 & 0.053 \\
\hline & B733 & & 34.587 & 0.137 & 0.086 \\
\hline \multirow{7}{*}{ CCA1640 } & A321 & \multirow{7}{*}{$9.832 \mathrm{~h}$} & 24.449 & 0.248 & 0.06 \\
\hline & A332 & & 56.702 & 1.719 & 0.754 \\
\hline & B733 & & 36.677 & 0.209 & 0.053 \\
\hline & B737 & & 42.557 & 0.155 & 0.028 \\
\hline & B738 & & 42.212 & 0.199 & 0.048 \\
\hline & B744 & & 110.934 & 2.029 & 0.635 \\
\hline & B772 & & 47.416 & 0.449 & 0.11 \\
\hline \multirow{9}{*}{ CCA931 } & B733 & \multirow{9}{*}{$9.915 \mathrm{~h}$} & 1.364 & 0.115 & 0.008 \\
\hline & B737 & & 35.99 & 0.049 & 0 \\
\hline & B738 & & 37.702 & 0.046 & 0 \\
\hline & B744 & & 90.3 & 2.238 & 0.539 \\
\hline & B752 & & 27.352 & 0.051 & $\mathbf{0}$ \\
\hline & A320 & & 27.393 & 0.369 & 0.048 \\
\hline & A319 & & 13.292 & 0.025 & $\mathbf{0}$ \\
\hline & A321 & & 22.382 & 0.13 & 0.011 \\
\hline & A330 & & 40.187 & 1.252 & 0.0356 \\
\hline \multirow{9}{*}{ CCA1858 } & A321 & \multirow{9}{*}{$9.237 \mathrm{~h}$} & 23.453 & 0.146 & 0.036 \\
\hline & A333 & & 58.148 & 1.561 & 0.709 \\
\hline & B737 & & 45.426 & 0.079 & 0.003 \\
\hline & B738 & & 45.693 & 0.081 & 0.005 \\
\hline & B744 & & 113.744 & 2.031 & 0.595 \\
\hline & B752 & & 32.239 & 0.075 & 0.007 \\
\hline & B762 & & 86.784 & 0.688 & 0.141 \\
\hline & B763 & & 103.23 & 0.858 & 0.54 \\
\hline & B772 & & 49.93 & 0.17 & 0.027 \\
\hline \multirow{7}{*}{ CCA1610 } & B733 & \multirow{7}{*}{$11.57 \mathrm{~h}$} & 22.328 & 0.079 & 0.01 \\
\hline & B737 & & 24.718 & 0.038 & 0.001 \\
\hline & B738 & & 23.632 & 0.045 & 0.001 \\
\hline & B752 & & 17.314 & 0.047 & 0.001 \\
\hline & B763 & & 68.577 & 0.577 & 0.084 \\
\hline & A319 & & 8.004 & 0.029 & 0 \\
\hline & A321 & & 15.234 & 0.099 & 0.017 \\
\hline \multirow{3}{*}{ CDG4855 } & B733 & \multirow{3}{*}{$12.75 \mathrm{~h}$} & 44.554 & 0.226 & 0.044 \\
\hline & B737 & & 52.618 & 0.147 & 0.01 \\
\hline & B738 & & 50.265 & 0.134 & 0.013 \\
\hline & A321 & & 45.448 & 0.734 & 0.156 \\
\hline & B733 & & 56.656 & 0.256 & 0.053 \\
\hline CCA1654 & B737 & $8.785 \mathrm{~h}$ & 66.27 & 0.165 & 0.016 \\
\hline & B738 & & 69.036 & 0.146 & 0.02 \\
\hline & B763 & & 149.026 & 1.447 & 0.299 \\
\hline
\end{tabular}




\subsection{Experimental Analysis}

In order to explore the reasons that different aircraft types performing the same flight task generate different noise level, this article conducts the research of the internal structure of aircraft. This paper studies the thrust, the number of engine and maximum gliding distance when landing from Integrated Noise Model (INM), as shown in Table 4. It can be seen from the Table, number of engines, maximum static thrust, maximum gross landing weight and maximum landing weight are relatively small. And it is the root cause that A319 generates minimal noise effect. Noise generated by aircraft is mainly limited to the net thrust of aircraft, and in all the models A319 is with minimal thrust of landing.

Table 4. The Information about the Internal Structure of Aircraft

\begin{tabular}{clclll}
\hline $\begin{array}{c}\text { Aircraft } \\
\text { Model }\end{array}$ & $\begin{array}{l}\text { Weight } \\
\text { Class }\end{array}$ & $\begin{array}{l}\text { Engine } \\
\text { Number }\end{array}$ & $\begin{array}{l}\text { Maxinum } \\
\text { Gross Landing } \\
\text { Weight }\end{array}$ & $\begin{array}{l}\text { Maximum } \\
\text { Landing } \\
\text { Distance }\end{array}$ & $\begin{array}{l}\text { Maxi-num } \\
\text { static thrust }\end{array}$ \\
\hline A319 & Large & 2 & $137800 \mathrm{lb}$ & $4740 \mathrm{ft}$ & $22000 \mathrm{lb}$ \\
A321 & Large & 2 & $171500 \mathrm{lb}$ & $5440 \mathrm{ft}$ & $30000 \mathrm{lb}$ \\
B752 & Large & 2 & $210000 \mathrm{lb}$ & $4640 \mathrm{ft}$ & $40100 \mathrm{lb}$ \\
B733 & Large & 2 & $114000 \mathrm{lb}$ & $4580 \mathrm{ft}$ & $20000 \mathrm{lb}$ \\
B737 & Large & 2 & $129200 \mathrm{lb}$ & $4445 \mathrm{ft}$ & $24000 \mathrm{lb}$ \\
B738 & Large & 2 & $146300 \mathrm{lb}$ & $5435 \mathrm{ft}$ & $27300 \mathrm{lb}$ \\
B744 & Heavy & 4 & $652000 \mathrm{lb}$ & $6989 \mathrm{ft}$ & $56800 \mathrm{lb}$ \\
A330 & Heavy & 2 & $412300 \mathrm{lb}$ & $5126 \mathrm{ft}$ & $71100 \mathrm{lb}$ \\
A320 & Large & 2 & $145505 \mathrm{lb}$ & $4911 \mathrm{ft}$ & $25000 \mathrm{lb}$ \\
\hline
\end{tabular}

\section{Conclusion}

The paper finds the phenomenon of different aircraft models performing the same flight is widespread through the analysis of noise monitoring data of Capital Airport. And further validates that different aircraft models performing the same flight generate significantly different noise.

The research of aircraft type selection of single flight for noise reduction carries out in this article, And we model this problem as a multi-objective optimization problem, which describes each sub-goal as the area of each segment decibels affected by different models performing the specific flight event.

Experimental results show that the proposed algorithm can select the model with the smallest noise, and prove the effectiveness of the proposed algorithm by analyzing the correlation between thrust of aircraft models and landing distance.

\section{Acknowledgments}

This work is supported by National Natural Science Foundation of China under Grant 61139002, Ministry of Science and Technology under Grant 2012AA06330, Civil Aviation Administration of China under Grant MHRD201101. This work is also supported by Fundamental Research Funds for the Central Universities under Grant 3122013P013 and 3122013C005.

\section{References}

[1] P. Jiao and L. C. Cai, "Annoyance of Aircraft Noise in Military Airfields", Environmental Science \& Technology, (2008), pp. 50-52.

[2] D. S. Zachary, J. Gervais and U. Leopold, "Strategic Planning of Aircraft Movements with a ThreeCost Objective", Journal of Aircraft, (2011), pp. 256-264.

[3] "CCAR-36 board. Beijing: Civil Aviation Administration of China", (2007).

[4] H. G. Visser, S. J. Hebly and R. A. A. Wijnen, "Improving the management of the environmental impact of airport operations", New Transportation Research Progress (2008), pp.1-65. 
[5] J. A. Zalovcik and W. T. Schaefer, "NASA research on noise-abatement approach profiles for multiengine jet transport aircraft", National Aeronautics and Space Administration, (1967).

[6] B. R. Den, C. Beers and H. Huisman, "SOURDINE-II: SOME ASPECTS OF THE ASSESSMENT OF NOISE ABATEMENT PROCEDURES //6th FAA/EUROCONTROL ATM R\&D Seminar, (2005).

[7] R. Koenig, J. Heider and M. Maierhofer, "Aircraft flight procedure design with respect to noise abatement as well as economical and pilot workload aspects", (2005).

[8] X. Prats, F. Nejjari and V. Puig, "A framework for RNAV trajectory generation minimizing noise nuisances", Proceedings of the 2nd International Congress on Research in Air Transportation (ICRAT), Belgrade, Serbia, (2006).

[9] S. Alam, M. H. Nguyen and H. A. Abbass, "A dynamic continuous descent approach methodology for low noise and emission", Digital Avionics Systems Conference (DASC), IEEE/AIAA 29th, (2010), pp. 5-18.

[10] H. G. Visser, "Generic and site-specific criteria in the optimization of noise abatement trajectories", Transportation Research Part D: Transport and Environment, (2005), pp. 405-419.

[11] R. A. A. Wijnen and H. G. Visser, "Optimal departure trajectories with respect to sleep disturbance", Aerospace science and technology, vol. 7, no. 1, (2003), pp. 81-91.

[12] H. G. Visser and R. A. A. Wijnen, "Optimization of noise abatement arrival trajectories", Aeronautical Journal, vol. 107, no. 1076, (2003), pp. 607-616.

[13] X. Feng and X. G. Liu, "Method Based on Land Use Category for Comparison of Airport-NoiseAssessment Threshold Criteria", Environment Science \& Technology, vol. 36, no. 4, (2013), pp. 182185.

[14] K. M. Li, "Land Use Management and Airport Controls", FAA, (2008).

[15] D. Y. Tang, W. L. Li and W. Y. Qiao, "Airport Noise Basis", Northwestern Polytechnical University Press ( 1995).

[16] J.R. Olmstead, G.G. Fleming, J.M. Gulding, Integrated noise model (INM) Version 6.0 Technical manual, Federal Aviation Administration Office of Environment and Energy, Paper FAA-AEE-02-01 Washington, DC (2002).

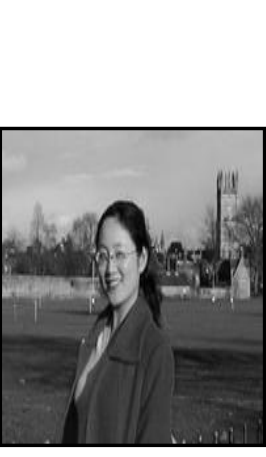

\section{Authors}

Feng Xia, received her ph.D. degree in College of Information Technical Science Nankai University, China, in 2005. Now she is a professor of the college of computer science and technology, Civil Aviation University. Her current reseach interests include data mining and intelligent information processing of civil aviation.

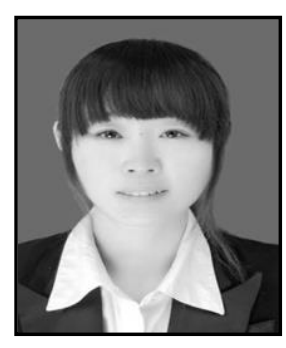

Sun Fangli, is a master candidate at college of computer science and technology, Civil Aviation University of China. She received her B.S degree in computer science and technology from Yantai University of China in 2012. Her current reseach interests include data mining and intelligent information processing of civil aviation.

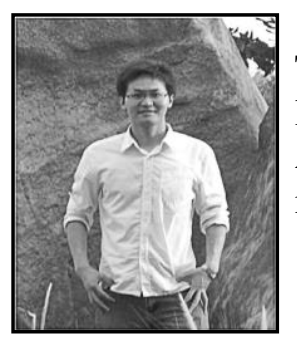

Lu Min, received her Ph.D. degree in College of Information Technical Science Nankai University, China, in 2013. Now he is a lecturer of the college of computer science and technology, Civil Aviation of University. His current reseach interests include data mining and intelligent information processing of civil aviation. 